УДК 910.26

ОЦЕНКА РЕКРЕАЦИОННОЙ НАГРУЗКИ НА ТЕБЕРДИНСКИЙ
ГОСУДАРСТВЕННЫЙ ПРИРОДНЫЙ БИОСФЕРНЫЙ ЗАПОВЕДНИК

Зеленская Т.Г., Степаненко Е.Е., Окрут С.В., Безгина Ю.А., Халикова В.А. ФГБОУ ВО «Ставропольский государственный аграрный университет», Ставрополь, e-mail: tamara.zelenskaya2016@yandex.ru

В статье отражены результаты рекреационной нагрузки на экосистему Тебердинского государственного природного биосферного заповедника. В Ставропольском крае развитие получили научные исследования, посвященные репрезентативности охраняемых территорий, так как рекреационный туризм очень развит в крае и относится к одному из самых динамично развивающихся и перспективных направлений не только в России, но и во всем мире. Залогом устойчивого развития рекреационных территорий является не что иное, как рациональное природопользование, основанное на достоверной информации о состоянии окружающей среды. В этом случае экологический мониторинг рекреационных ландшафтов является важным звеном в развитии рекреационной деятельности с учетом экологических условий территории. Но рекреационная привлекательность, в свою очередь, влечет антропогенную нагрузку на экосистему Тебердинского государственного природного биосферного заповедника, поэтому развитие экологического мониторинга на данной территории позволит изучить состояние туристических троп и применить эти данные в работе с экскурсантами. Несмотря на то что в настоящее время бурными темпами идет развитие экотуризма, многие исследователи констатируют недостаточный уровень экологического просвещения современного туриста. В результате интенсивного развития экологического и рекреационного туризма проявляются процессы вытаптывания почв, гибели молодого подроста растений, спрессования листовой подстилки. Увеличение потока туристов приводит и к снижению видового разнообразия флоры и фауны. На экологическое и санитарное состояние рекреационных местностей также влияют отходы потребления, оставляемые туристами, и отходы производства различных предприятий, выбросы автотранспорта. В результате снижается показатель комфортности отдыха и, соответственно, показатель посещаемости данной рекреации. Рекреационные районы испытывают на себе постоянно нарастающий антропогенный пресс, изучение специфики и особенностей конкретного региона является одним из направлений современных научных исследований. В связи с этим представляются актуальными работы по определению влияния антропогенной нагрузки на Тебердинский государственный природный биосферный заповедник.

Ключевые слова: антропогенное воздействие, экологический туризм, заповедник, рекреационный туризм, рекреационная привлекательность

\title{
ASSESSMENT OF RECREATION LOAD ON THE TEBERDIN STATE NATURAL BIOSPHERE RESERVE
}

\author{
Zelenskaya T.G., Stepanenko E.E., Okrut S.V., Bezgina Yu.A., Khalikova V.A. \\ Stavropol State Agrarian University, Stavropol,e-mail: tamara.zelenskaya2016@yandex.ru
}

The article reflects the results of the recreational load on the ecosystem of the Teberda State Natural Biosphere Reserve. In the Stavropol Territory, scientific research devoted to the representativeness of protected areas has developed, since recreational tourism is very developed in the region and belongs to one of the most dynamically developing and promising directions not only in Russia, but throughout the world. The key to their sustainable development of recreational areas is nothing more than rational nature management based on reliable information about the state of the environment. In this case, ecological monitoring of recreational landscapes is an important link in the development of recreational activities, taking into account the ecological conditions of the territory. But the recreational attractiveness, in turn, entails an anthropogenic load on the ecosystem of the Teberda State Natural Biosphere Reserve, therefore, the development of environmental monitoring in this area will allow studying the state of tourist trails and applying these data in work with tourists. Despite the fact that ecotourism is currently developing at a rapid pace, many researchers state the insufficient level of environmental education of the modern tourist. As a result of the intensive development of ecological and recreational tourism, the processes of trampling of soils, the death of young undergrowth of plants, and the compaction of leaf litter are manifested. An increase in the flow of tourists also leads to a decrease in the species diversity of flora and fauna. The ecological and sanitary state of recreational areas is also influenced by consumer waste left by tourists and industrial waste from various enterprises, vehicle emissions. As a result, the indicator of the comfort of rest decreases, and, accordingly, the indicator of the attendance of this recreation. Recreational areas are experiencing a constantly growing anthropogenic pressure, the study of the specifics and characteristics of a particular region is one of the directions of modern scientific research. In this regard, it seems relevant to work on determining the impact of anthropogenic load on the Teberda State Natural Biosphere Reserve.

Keywords: anthropogenic impact, ecological tourism, nature reserve, recreational tourism, recreational attractiveness

В настоящее время бурными темпам идет развитие экотуризма, многие исследователи констатируют недостаточный уровень экологического просвещения современного туриста. Экологическая без- грамотность наносит значительный вред окружающей среде. Очень актуально эта проблема рассматривается на особо охраняемых природных территориях, где результаты туристической деятельности несут 
большой урон экосистеме заповедников. Рациональное использование рекреационного туризма должно строиться на определении предельно допустимых нагрузок, соответственно, оценка качества окружающей среды, ее благоприятности для человека является одним из основополагающих моментов в решении природоохранных задач [1].

Целью исследования явилось определение рекреационной нагрузки на Тебердинский государственный природный биосферный заповедник.

\section{Материалы и методы исследования}

Работа выполнена на основе полевых экспедиционных исследований 20152019 гг. в летние периоды сотрудниками кафедры экологии и ландшафтного строительства Ставропольского государственного аграрного университета и по данным Тебердинского государственного природного биосферного заповедника, в результате которых был собран обширный материал и проведены расчеты «пределов допустимых изменений» на экомаршруте «Алибек Турье озеро» в заповеднике по методике А.Д. Калихмана [2]. Обработка данных проводилась на кафедре экологии и ландшафтного строительства в лаборатории экологического мониторинга Ставропольского государственного аграрного университета. Метод анкетирования нами использовал- ся с последующим анализом полученной информации о посещаемости туристами и отдыхающими рекреационных зон. Для эффективного рекреационного лесопользования определяют рекреационную емкость (РЕ) экосистемы, которая измеряется количеством посещений в человеко-часах на 1 га в год. Для выявления эколого-рекреационной емкости (ЭРЕ), а затем и рекреационно-ресурсного потенциала (РРП) объекта вычисляли допустимую для него рекреационную нагрузку, которая не вызывает необратимых изменений [3]. Определяется данный показатель количеством рекреантов на единице площади, временем их пребывания на объекте рекреации и видом отдыха. Измеряли рекреационную нагрузку за каждый час наблюдений (чел. - ч/га). Для этого в течение часа фиксировали изменения единовременной плотности туристов и временные интервалы этих изменений.

\section{Результаты исследования и их обсуждение}

Развитие туризма в последнее время приобретает массовый характер, а развитие туризма в ООПТ имеет в основном негативное воздействие, положительных моментов очень мало. Постоянный приток туристов, развитие инфраструктуры и многое другое очень негативно сказываются на состоянии окружающей среды.

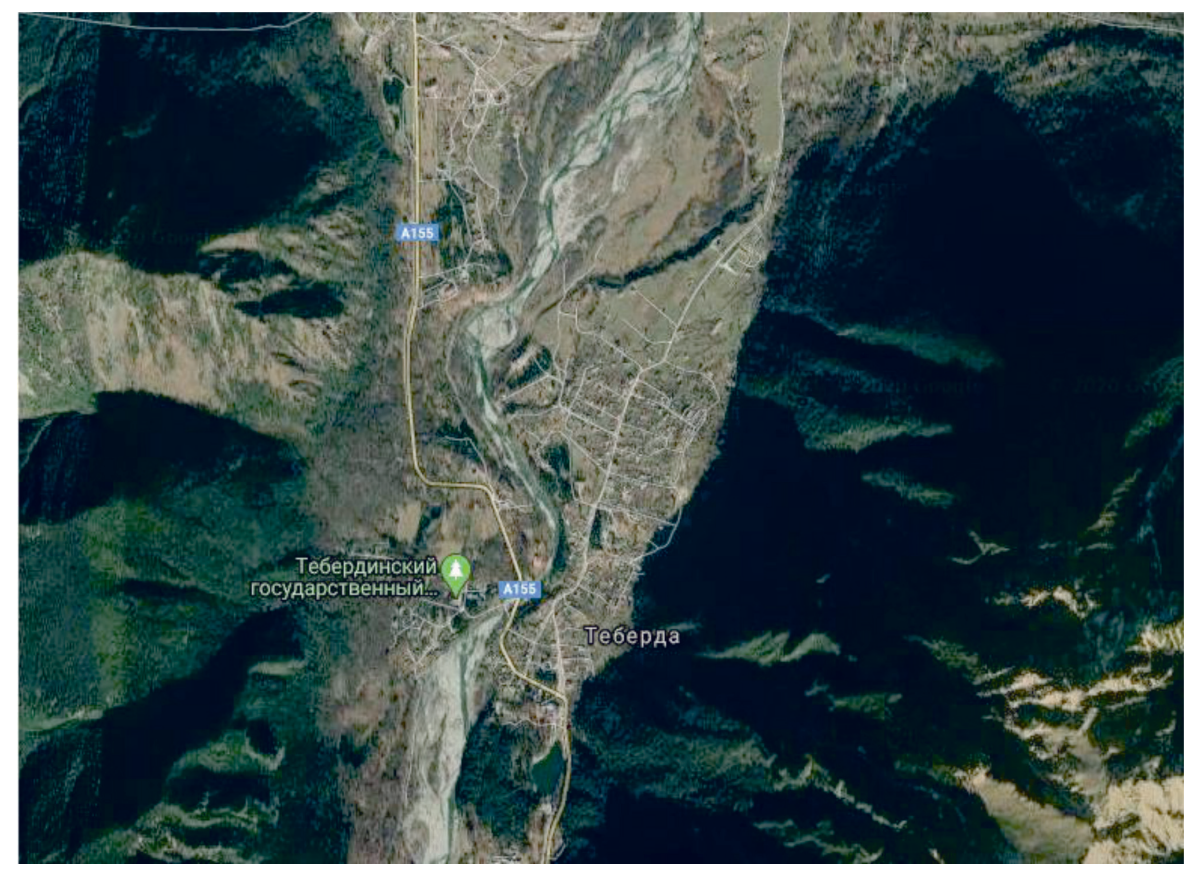

Рис. 1. Карта расположения Тебердинского государственного природного биосферного заповедника (http://u-karty.ru/sputnik/teberda-so-sputnika.html) 
Руководство заповедника активно внедряет все формы экотуризма и приветствует его развитие. Но рекреационная привлекательность, в свою очередь, влечет антропогенную нагрузку на экосистему заповедника, поэтому развитие экологического мониторинга на данной территории позволит изучить состояние туристических троп и применить эти данные в работе с экскурсантами [4]. При расчете емкости комплекса отдыха прямое использование полученных величин предельных нагрузок дает неверные результаты. Одна из причин заключается в необоснованной для этих целей единице времени - 1 ч. Дело в том, что отдыхающие проходят по территории отдыха в течение всего светового дня (с 9 до 19 ч).

Таким образом, рекреационная нагрузка на данную территорию за день составит величину в 10 раз большую, чем рассчитанная в чел/га. Однако и эта единица измерения - чел/га в день - не может быть принята за основу, так как в течение дня одни и те же отдыхающие могут проходить по территории отдыха несколько раз. При этом фактическое количество отдыхающих будет ниже того, которое эквивалентно их воздействию на природный комплекс [5]. Количество посетителей заповедника за 2015-2019 гг. представлено на рис. 2.

Анализ рисунка показывает, что наибольшее количество посетителей наблюдалось в 2017 и 2019 годах. Это связано с тем, что 16.07.2016 г. был открыт инфор- мационный Визит-центр для посетителей, и в это же время прошло празднование 80-летия заповедника. И, соответственно, это привлекло новых посетителей.

Динамика посещаемости заповедника за период с 2015 по 2019 г. представлена на рис. 3. Пики сезонного рекреационного использования показывают, что больше всего посетителей на рекреационной территории летом для отдыха и восстановления сил и зимой - для занятия спортом.

Таким образом, при расчете емкости комплекса отдыха рекреационные нагрузки выступают в качестве исходных величин, а плотности отдыхающих как промежуточные.

С целью изучения востребованности заповедника в качестве рекреационного pecypca нами было проведено анкетирование рекреантов. Всего было опрошено 104 человека.

Данные социологического опроса позволили установить, что рекреационная активность туристов, посещающих территорию заповедника с целью осуществления отдыха и рекреационного туризма, составляет: рекреантов, впервые посетивших территорию заповедника, - 58 человек; ежегодно приезжающих для отдыха именно в это место - 24 человека; остальные оказались там случайно или имеют нерегулярные выезды. Чаще всего территория заповедника посещается молодыми людьми (экологический туризм), людьми пенсионного возраста с детьми (в целях курортного лечения).

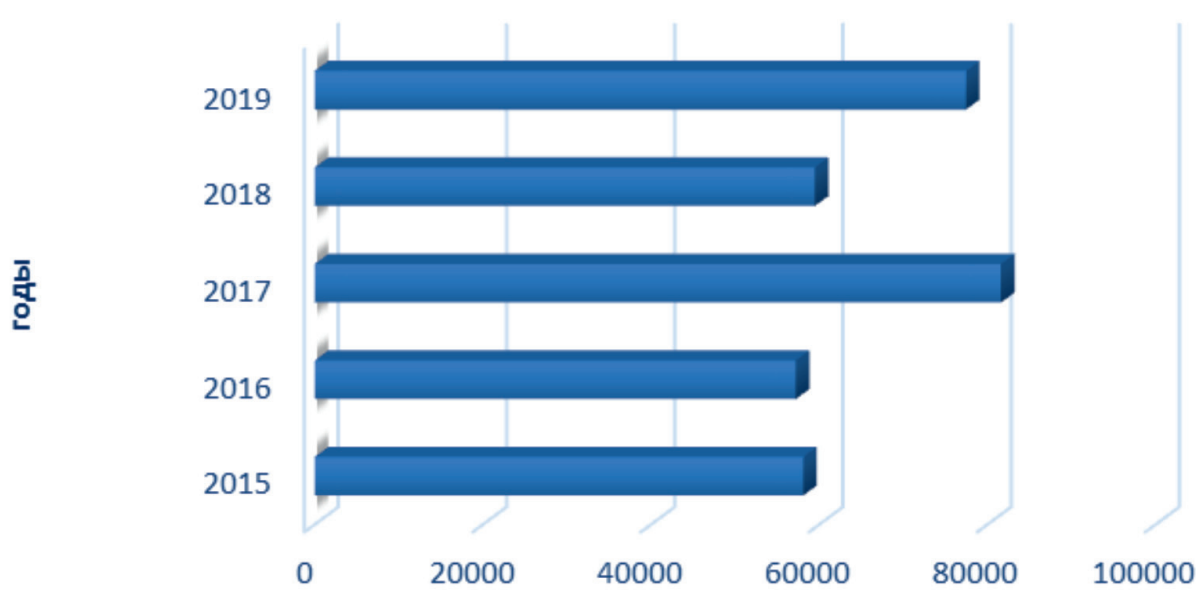

п количество посетителей

Рис. 2. Количество посетителей заповедника за 5 лет (2015-2019 г2.) 

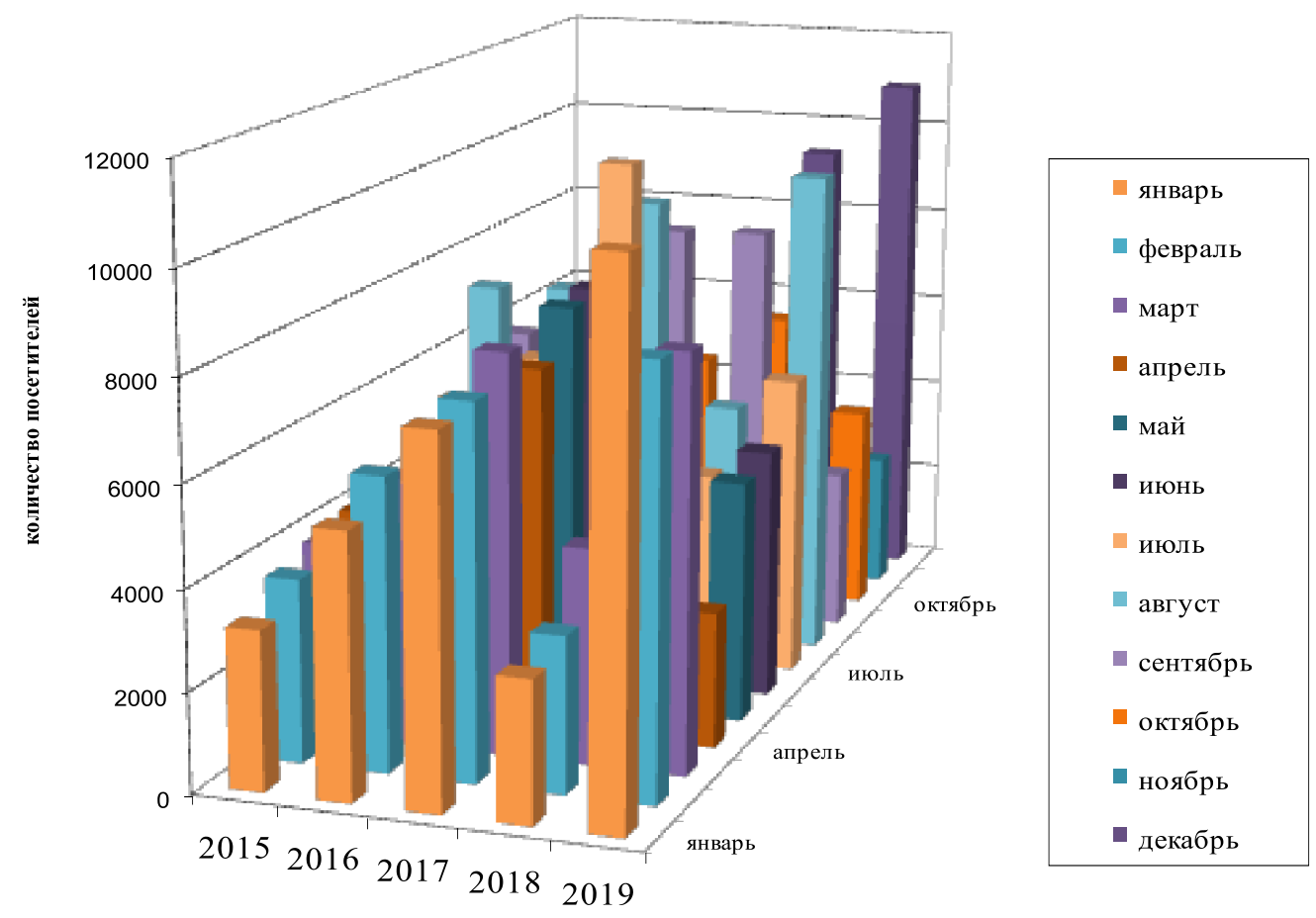

Рис. 3. Динамика посещуаемости заповедника с 2015 по 2019 г. по месяцам

На территории заповедника бывает много (из 104 опрошенных - 48) студентов, приезжающих с образовательными и просветительными целями. При изучении сезонного рекреационного использования было замечено, что больше всего людей предпочитает находиться на рекреационной территории летом для отдыха и восстановления сил, и зимой - для занятий спортом. Для этого в разное время (дни недели и сезоны) производился подсчет рекреантов, посещающих территорию заповедника. Данные отражены в табл. 1 и 2.

На наш взгляд, выявление данных закономерностей имеет большое практическое значение, так как связано с определенными пиками массового воздействия на экосистемы заповедника. Определяя рекреационную емкость (РЕ) экосистемы, мы выяснили, что рекреационная нагрузка бывает максимальной в весенне-летний и ранневесенний периоды и минимальной поздней осенью и зимой. Анализ таблицы показывает, что количество рекреантов, посещающих Тебердинский заповедник в будни и выходные, различается. Больше всего рекреантов посещают тропу экомаршрут «Алибек,
Турье озеро»: в будние дни - 42 человека, в выходные дни - 84 человека (из них большее количество приходится на молодежь, а наименьшее количество - на родителей с детьми). Участок леса в районе усадьбы заповедника посещает очень малое количество рекреантов: всего в будние дни 7 человек, а в выходные - 14 (и в основном это молодежь), по сравнению экомаршрутом «Алибек, Турье озеро».

На основании имеющихся данных по количеству рекреантов нами были сделаны расчёты по оценке ЭРЕ и РРП.

Сравнительная оценка ёмкости экологической рекреационной нагрузки на различных участках Тебердинского государственного природного биосферного заповедника приведена на рис. 4.

Из рис. 4 видно, что экологическая рекреационная нагрузка на тропе экомаршрута «Алибек, Турье озеро» составляет в будние дни - 19027,11 чел./год, а в выходные дни 55774,76 чел./год. В то же время рекреационная нагрузка на участке леса в районе усадьбы заповедника составляет в будние дни - 1674,059 чел./год, а в выходные дни 4532,209 чел./год. 
Таблица 1

Количество рекреантов, посещающих заповедник в будни и выходные

\begin{tabular}{|l|c|c|c|c|}
\hline \multirow{3}{*}{$\begin{array}{c}\text { Категория } \\
\text { посетителей }\end{array}$} & \multicolumn{4}{|c|}{$\begin{array}{c}\text { Количество рекреантов } \\
\text { Тукомаршрут «Алибек, }\end{array}$} \\
\cline { 2 - 5 } & \multicolumn{4}{|c|}{$\begin{array}{c}\text { Участок леса } \\
\text { в районе усадьбы заповедника }\end{array}$} \\
\cline { 2 - 5 } & Будни & Выходные & Будни & Выходные \\
\hline Пенсионеры & 10 & 11 & - & 2 \\
\hline Родители с детьми & 2 & 5 & 7 & 12 \\
\hline Молодёжь & 30 & 68 & 7 & 14 \\
\hline Всего & 42 & 84 & - & 12 \\
\hline
\end{tabular}

Таблица 2

Количество рекреантов, посещающих заповедник в различных по значимости зонах, чел./час

\begin{tabular}{|c|c|c|c|c|}
\hline $\begin{array}{c}\text { Время исследования, } \\
\text { дни }\end{array}$ & \multicolumn{2}{|c|}{$\begin{array}{c}\text { Тропа } \\
\text { (max), чел./час }\end{array}$} & \multicolumn{2}{c|}{$\begin{array}{c}\text { Участок леса в районе усадьбы } \\
\text { заповедника (min), чел./час }\end{array}$} \\
\cline { 2 - 5 } & Будни & Выходные & Будни & Выходные \\
\hline 1 & 17 & 38 & 2 & 4 \\
\hline 2 & 22 & 43 & 4 & 5 \\
\hline 3 & 19 & 34 & 3 & 5 \\
\hline 4 & 18 & 42 & 2 & 5 \\
\hline 5 & 16 & 36 & 5 & 5 \\
\hline 6 & 25 & 30 & 3 & 4 \\
\hline 7 & 20 & 47 & 2 & 6 \\
\hline 8 & 28 & 49 & 2 & 5 \\
\hline 9 & 24 & 55 & 3 & \\
\hline Среднее & 21 & 41 & & \\
\hline
\end{tabular}

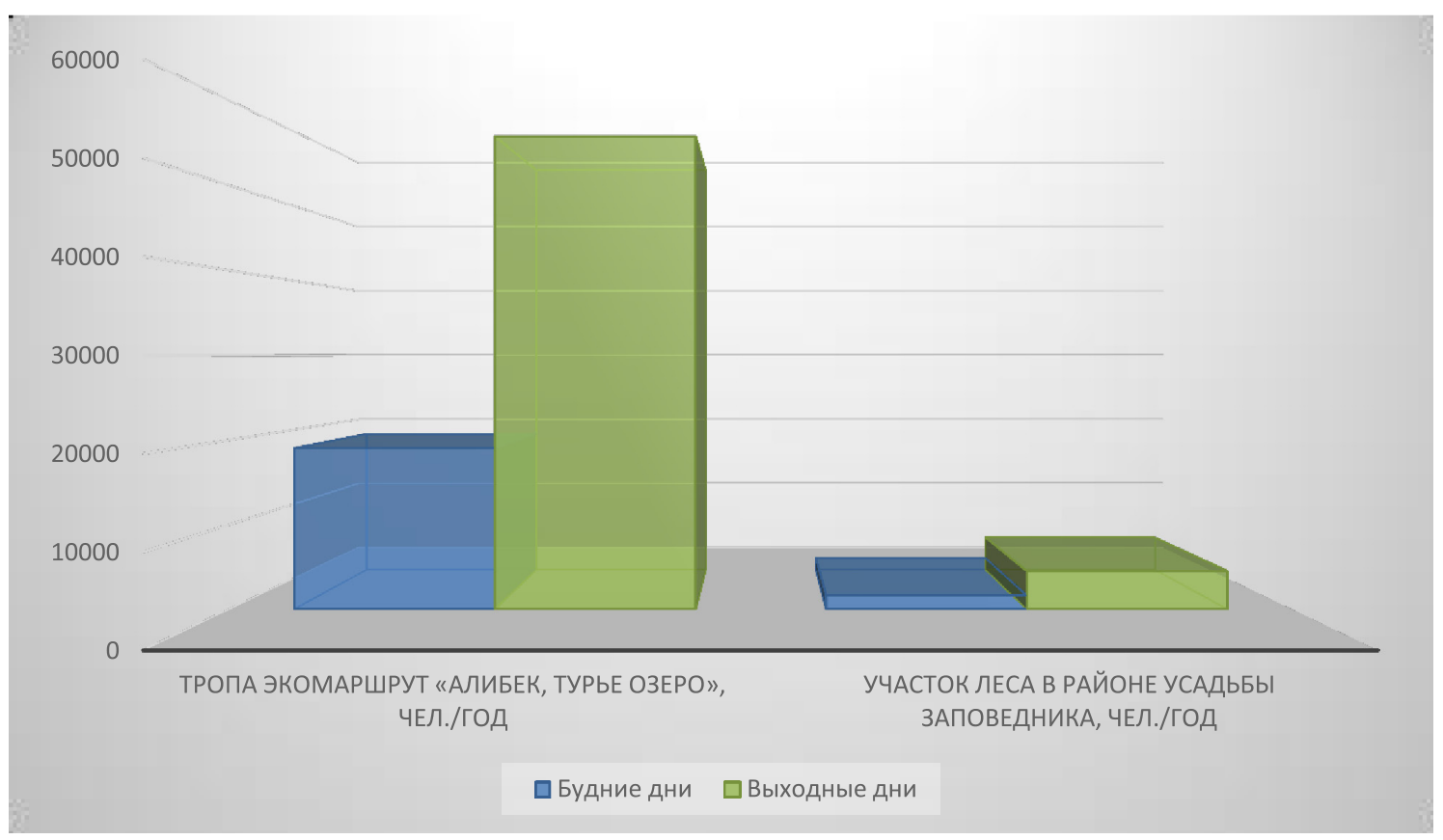

Рис. 4. Сравнительная оценка ёмкости экологической рекреаџионной нагрузки на различных участках заповедника, чел./год 


\section{Заключение}

Для уменьшения отрицательного влияния рекреационного лесопользования на леса и, соответственно, повышения их рекреационной емкости необходимо рекреационное благоустройство - организация системы дорожек, туалетов, ночевок, стоянок, организованных кострищ [6]. Установлены правила поведения людей в лесу, определены размеры штрафов, взимаемых с них за порчу природных объектов.

Таким образом, на основании расчётов и судя по состоянию окружающей среды, современная рекреационная нагрузка на территории Тебердинского заповедника может быть признана вполне допустимой [7]. В целом же степень и характер воздействия антропогенной деятельности на курортно-рекреационные ландшафты зависят от ряда факторов и индивидуальны для конкретных территорий.

\section{Список литературы / References}

1. Зеленская Т.Г., Степаненко Е.Е. Мониторинг антропогенного влияния особо охраняемых территорий // Образование. Наука. Производство. 2019. С. 49-51.

Zelenskaya T.G., Stepanenko E.E. Monitoring of the anthropogenic impact of specially protected areas // Obrazovanie. Nauka. Proizvodstvo. 2019. P. 49-51 (in Russian).

2. Калихман А.Д., Педерсен А.Д., Савенкова Т.П., Сукнев А.Я. Методика «Пределов допустимых изменений» на Байкале - участке Всемирного наследия ЮНЕСКО. Иркутск: Оттиск, 1999. 100 с.
Kalikhman A.D., Pedersen A.D., Savenkova T.P., Suknev A.Ya. Methodology «Limits of Permissible Changes» on Baikal - a UNESCO World Heritage Site. Irkutsk: Ottisk, 1999, 100 p. (in Russian).

3. Зеленская Т.Г., Степаненко Е.Е., Мандра Ю.А., Закрасняная В.Ю. Эколого-экономическая оценка средозащитной функции зеленых насаждений // Актуальные вопросы экологии и природопользования. 2017. С. 143-145.

Zelenskaya T.G., Stepanenko E.E., Mandra Yu.A., Zakrasnyana V.Yu. Ecological and economic assessment of the environmental protection function of green spaces // Aktual'nyye voprosy ekologii i prirodopol'zovaniya. 2017. P. 143145 (in Russian).

4. Павлов А.В., Братков В.В. Мониторинг верхней границы леса Тебердинского заповедника (по материалам дистанционного зондирования) // Мониторинг. Наука и технологии. 2017. № 3 (32). С. 50-56.

Pavlov A.V., Bratkov V.V. Monitoring of the upper forest boundary of the Teberdinsky Reserve (based on remote sensing materials) // Monitoring. Nauka i tekhnologii. 2017. No. 3 (32). P. 50-56 (in Russian).

5. Савельева В.В., Шальнев В.А. Рекреационные оценки природных комплексов Архыза // Вопросы рекреационной географии Северного Кавказа. Ставрополь, 1977. 83 с.

Savelyeva V.V., Shalnev V.A. Recreational assessments of natural complexes of Arkhyz // Voprosy rekreatsionnoy geografii Severnogo Kavkaza. Stavropol, 1977. 83 p. (in Russian).

6. Кнестикова М.M. Необходимость ведения красной книги на Ставрополье // Молодежь - науке: образование, экология, традиции. Ставрополь, 2019. С. 131-134.

Knestikova M.M. The necessity of maintaining a red book in Stavropol // Molodezh' - nauke: obrazovaniye, ekologiya, traditsii. Stavropol, 2019. P. 131-134 (in Russian).

7. Примаченко Е.И., Ткачева А.Ю. Составление туристской карты на территорию Тебердинского заповедника // Огарёв-Online. 2019. № 3 (124). С. 7.

Primachenko E. I., Tkacheva A. Yu. Drawing up a tourist map of the Teberdinsky nature reserve // Ogarev-Online. 2019. № 3 (124). P. 7 (in Russian). 